\title{
Airway Management Recommendations in Coronavirus Disease 2019 (Covid-19) Patients
}

\author{
Luis Leobardo Fortis Olmedo ${ }^{1 *}$, Diana Stephanie Calva Ruiz ${ }^{2}$, Armida Pineda Rivera ${ }^{1}$ and Cristian Irvin \\ Ham Armenta ${ }^{2}$
}

${ }^{1}$ Anesthesiologist, The American British Cowdray Medical Center IAP, Mexico

${ }^{2}$ Anesthesiology Resident, Hospital Ángeles Interlomas, Mexico

*Corresponding author: Luis Leobardo Fortis Olmedo, Anesthesiologist, The American British Cowdray Medical Center IAP, Mexico.

Received Date: March 18, 2020

Published Date: April 09, 2020

\begin{abstract}
Summary
Coronavirus pandemic (COVID-19) is a public health problem, in which the aerosol generation place the anaesthesiologist in a high risk of contagion and in a high level of stress. In the following review we make recommendations on best practice in airway management in patients suspected of COVID-19.
\end{abstract}

\section{Introduction}

Since the emergence of the new 2019 coronavirus infection (2019-CoV) in Wuhan, China, it has spread rapidly throughout China and in more than 100 countries today. Clinical data has shown that the symptom onset date of the first known patient was December 1, 2019. The incubation period is known to be 1-14 days, so it is likely that inter-species transmission could have occurred from November 2019. On January 12, 2020, the World Health Organization (WHO) tentatively named this new virus as the new coronavirus 2019 (2019-nCoV). On January 30, 2020, the WHO announced the 2019-nCoV epidemic, the sixth public health emergency of international concern after H1N1 (2009), Polio (2014), Ebola in West Africa (2014), Zika (2016), and Ebola in the Democratic Republic of the Congo (2019). On February 11, 2020, the WHO announced a new name for the 2019-nCoV epidemic disease: coronavirus disease (COVID-19). On the same day, the coronavirus study group of the International Committee on Virus Taxonomy named 2019 - nCoV as Severe Acute Respiratory Syndrome of Coronavirus 2 (SARS-CoV-2). On March 11 the WHO declares COVID-19 as pandemic [1-3].

\section{Discussion}

It is relevant for the anaesthesiologist to care for patients with COVID-19 and other highly contagious respiratory diseases

since they are at high risk of contracting the infection. Airway management such as non-inasive ventilation (NIV), high-flow nasal cannula, bag mask ventilation, and especially orotracheal intubation is considered an extremely high risk, since the generation of aerosols is elevated with these procedures, they require special consideration and care when handling the patient's airway [47]. All medical staff involved in the management of patients with suspected COVID-19 must comply with standard precautions, protective actions, and cleaning and disinfection of the equipment. All aerosol generation procedures should be performed in an airborne infection isolation room.

\section{Standard Precautions}

Hand hygiene should be done with soap or alcohol-based agents, 95\% ethanol has been shown to be effective in removing most clinically relevant viruses, this action should be done before and after having contact with patients or material potentially infectious, and before and after the use of personal protective equipment [4].

Eye protection, with face mask or protective glasses, since the ocular mucosa is both a route of entry for infections and a potential site for viral replication [4-7]. Gloves must be double gloved since 
the outer gloves must be removed immediately after handling the airways, and medical staff must remove the inner gloves and perform hand hygiene. This provides additional protection and minimizes spread through contamination by fomites after intubation [6-9]. Aerosols ( $\leq 5 \mathrm{mcm}$ ) can remain airborne for long periods of time and, as a result, can also be transmitted over long distances [4]. Therefore, respiratory protection devices must be used. The most used $\mathrm{z}$ respiratory devices to prevent transmission of infectious agents in the air are masks and medical respirators [4-6].

Table 1: Airway management recommendations in coronavirus disease 2019 (covid-19) patients.

\begin{tabular}{|c|c|}
\hline \multicolumn{2}{|r|}{ Airway Management Recommendations } \\
\hline \multirow{3}{*}{$\begin{array}{l}\text { Standar } \\
\text { precautions }\end{array}$} & Hand hygiene \\
\hline & Eye protection \\
\hline & Doble gloves wearing \\
\hline \multirow{3}{*}{$\begin{array}{l}\text { Respiratory } \\
\text { protection }\end{array}$} & N95 masks \\
\hline & Air purifying respirators (APR) \\
\hline & Combination of both \\
\hline \multirow{4}{*}{ Preoxigenation } & With $100 \%$ oxygen \\
\hline & Avoid positive airway pressure \\
\hline & Avoid oropharyngeal os nasopharyngeal cannulas \\
\hline & Preoxygenation with CPAP \\
\hline \multirow{8}{*}{ Intubation } & Early intubation \\
\hline & Decrease intubation attempts \\
\hline & Perform intubation by the most experienced staff \\
\hline & Perform rapid sequence intubation (RSI) \\
\hline & Deep anesthesia and neuromuscular blockade \\
\hline & Use of disposable laryngoscopes as much as possible \\
\hline & Avoid awake patient intubation \\
\hline & $\begin{array}{l}\text { Inflate tube cuff immediately once the patient is } \\
\text { intubated }\end{array}$ \\
\hline \multirow{5}{*}{$\begin{array}{l}\text { Ventilation } \\
\text { methods }\end{array}$} & Avoid manual ventilation with positive pressure \\
\hline & Orotracheal intubation over a supraglottic device \\
\hline & Avoid non invasive ventilation \\
\hline & Avoid the use of high flow nasal tips \\
\hline & Avoid high flow devices (>6 L/min) \\
\hline $\begin{array}{l}\text { Decreased } \\
\text { fomites }\end{array}$ & $\begin{array}{l}\text { Avoid the use of electronic devices in the operating } \\
\text { room (cell phones, tablets or computers) }\end{array}$ \\
\hline \multirow{3}{*}{ Extubation } & After extubation, patient must use a mask \\
\hline & $\begin{array}{l}\text { Suplementary oxygen through nasal tips under the } \\
\text { facial mask }\end{array}$ \\
\hline & Patient recovery in the operating room \\
\hline
\end{tabular}

Standard masks are designed to prevent droplets from coming into contact with the user, they are not adjusted or designed to filter out smaller airborne infectious agents, although the use of N95 mask is controversial for several reasons, it is still recommended during most aerosol generating procedures (Figure 1). Air purification devices provide a higher level of protection than N95 masks, however, they are expensive, require proper cleaning and maintenance, and can interfere with airway management. However, in the context of highly infectious agent, PAPRs are the equipment of choice.

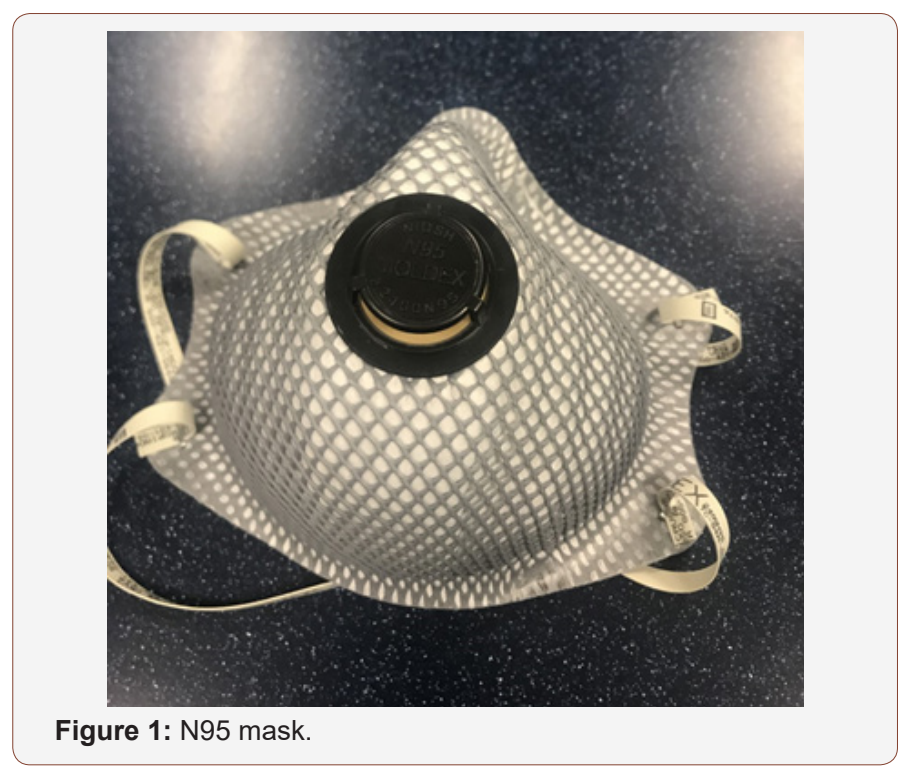

\section{Airway Management}

To reduce risks to both, patient and medical staff, patients infected with COVID-19, should only be operated if an emergency or non-elective surgery must be performed [8-10]. A meeting with the team should be held before surgery. This ensures that all necessary medications and equipment have been prepared, minimizing the need to leave and re-enter the operating room to bring the missing equipment. Infection prevention involves reducing aerosol generating procedures (airway manipulation, mask ventilation, open airway suction or patient's cough) [8]. Pre-oxygenation must be performed with 100\% oxygen with apneic techniques, avoiding positive pressure with bag-mask as far as possible. Exhalation, being a passive process, can increase the generation of aerosols when using a pharyngeal cannula, so they should be avoided as long as the patient tolerates apneic preoxygenation. Adequate anaesthetic depth and muscle relaxation are essential for intubation, so the use of electroencephalographic and neuromuscular monitoring with a train of four are essential [8]. Awake intubation techniques should be avoided because both the patient's cough and the atomized local anaesthetic can lead to aerosolization of the virus $[4,7,9]$. Non-invasive positive pressure ventilation should be avoided. Since the endotracheal tube has a better seal, it is always preferable for a definitive airway device, over a supraglottic airway device. The use of a video laryngoscope is recommended from the first attempt of intubation, because the respiratory protection devices can hinder vision during direct laryngoscopy, it also keeps the user further away from the patient's airway during intubation [5-9]. Rapid sequence induction should be perform in all patients, to reduce the need of bag-mask ventilation, the use of rocuronium as a muscle relaxant over succinylcholine is recommended for the neuromuscular block duration, and thus decrease the risk of cough [5-9]. After intubation, the cuff should be inflated, and the circuit connected prior the initiation of positive 
pressure ventilation [8]. After extubation, the patient should wear a surgical mask. Supplemental oxygen can be administered through nasal tips under the face mask. The patient must recover in the Operating room [8].

\section{Conclusion}

Due to COVID-19 is an infectious disease, caused by a new virus, there is a few information about this topic, and there is no vaccine or specific treatment. So currently the recommendations are based on prevent the infection. Health personnel who is in charge of the airway management with suspicious infected patients must know these recommendations in order to avoid aerosols generation.

\section{Acknowledgement}

None.

\section{Conflict of Interest}

No conflict of interest.

\section{References}

1. Xu Y (2020) Unveiling the Origin and Transmission of 2019-nCoV. Trends Microbiol 28(4): 239-240.
2. Lai C, Shih T, Ko W, Tang H, Hsueh P (2020) Severe acute respiratory syndrome coronavirus 2 ( SARS-CoV-2 ) and coronavirus disease-2019 ( COVID-19): The epidemic and the challenges. Int J Antimicrob Agents 55(3): 105924.

3. Sun P, Lu X, Xu C, Sun W, Pan B (2020) Understanding of COVID-19 based on current evidence. J Med Virol (February):1-4.

4. Ceschim MRS, Candiotti KA (2019) Airway Management in Highly Infectious Diseases: The Reemergence of Measles. Anesthesiol News : 91-96.

5. Cheung JCH, Ho LT, Cheng JV, Cham EYK, Lam KN (2020) Staff safety during emergency airway management for COVID-19 in Hong Kong. Lancet Respir Med 8(4): e19.

6. Zuo M, Huang Y, Ma W, Xue Z, Zhang J, et al. (2020) Expert Recommendations for Tracheal Intubation in Critically ill Patients with Noval Coronavirus Disease 2019. Chinese Med Sci J 1-9.

7. Peng PWH, Ho P, Hota SS (2020) Outbreak of a new coronavirus : what anaesthetists should know. Br J Anaesth (30): 1-5.

8. Wong J, Goh Q, Tan Z, Lie S, Tay Y, et al. (2020) Preparing for a COVID-19 pandemic : a review of operating room outbreak response measures in a large tertiary hospital in Singapore. Can J Anesth

9. Wax RS, Christian MD (2020) Practical recommendations for critical care and anesthesiology teams caring for novel coronavirus ( 2019$\mathrm{nCoV}$ ) patients. Can J Anesth

10. Wen X, Li Y (2020) Anesthesia Procedure of Emergency Operation for Patients with Suspected or Confirmed COVID-19. Surg Infect (Larchmt) 21(3): 299. 